\title{
COVID-19 in Lishui City of Zhejiang Province, China: An Epidemiological and Clinical Study
}

Dajin Zhou ${ }^{1}$, Wei Wang ${ }^{2}$, Ningjun $\mathrm{Wu}^{2}$, Wugao Liu ${ }^{2}$, Yiping Zhang ${ }^{1}$, Xiumei Yan $^{1}$, and youjun Feng ${ }^{3}$

${ }^{1}$ The Second People's Hospital of Lishui

${ }^{2}$ Clinical Laboratory of Lishui People's Hospital

${ }^{3}$ Affiliation not available

May 6, 2020

\begin{abstract}
The 2019 novel coronavirus disease (COVID-19) is an emerging pandemic caused by the highly-transmissible SARS-CoV-2 , posing a serious challenge to public health and clinical therapies worldwide. Very recently, we addresed a cluster of imported italian cases of COVID-19 in Lishui City, Zhejiang Province of China. Here we report an epidemiological and clincial study of local COVID-19 in Lishui City. This is a snapshot for comprehensive COVID-19 repertoires in Zhejiang, China.
\end{abstract}

\section{Hosted file}

2020_Feng_COVID-19 in Lishui City, China 3.doc available at https://authorea.com/ users/318566/articles/448426-covid-19-in-lishui-city-of-zhejiang-province-china-anepidemiological-and-clinical-study 